Pharmacogenomics. 2014 January ; 15(1): 69-78. doi:10.2217/pgs.13.228.

\title{
Pharmacogenetics and individualizing drug treatment during pregnancy
}

\author{
David M Haas \\ Department of OB/GYN, Indiana University School of Medicine, 1001 W. 10th Street, F5102, \\ Indianapolis, IN 46202, USA, Tel.: +1 3176307837 \\ David M Haas: dahaas@iupui.edu
}

\begin{abstract}
Pharmacogenetics as a tool to aid clinicians implement individualized pharmacotherapy is utilized in some areas of medicine. Pharmacogenetics in pregnancy is still a developing field. However, there are several areas of obstetric therapeutics where data are emerging that give glimpses into future therapeutic possibilities. These include opioid pain management, antihypertensive therapy, antidepressant medications, preterm labor tocolytics, antenatal corticosteroids and drugs for nausea and vomiting of pregnancy, to name a few. More data are needed to populate the therapeutic models and to truly determine if pharmacogenetics will aid in individualizing pharmacotherapy in pregnancy. The objective of this review is to summarize current data and highlight research needs.
\end{abstract}

\section{Keywords}

pharmacogenetics; pregnancy; therapeutics

\begin{abstract}
The right drug, at the right dose, given at the right time, for the right patient. This is an ideal that all healthcare practitioners strive toward when prescribing drugs to patients. This is particularly important for medications and conditions that have a high risk of adverse events or for drugs with narrow therapeutic windows. Additionally, pregnancy is a condition that is particularly enticing for the above mantra. Because of the presence of the developing fetus and the maternal changes that are occurring, pregnancy therapeutics offers particular challenges for the clinician. The goals of individualizing pharmacotherapy in pregnancy require information and tools to truly optimize care.
\end{abstract}

Pregnant women often need therapeutic drugs. Over $95 \%$ of women take a prescription drug or supplement during their pregnancy $[1,2]$. This includes over $65 \%$ of women taking a

\section{(C) 2014 Future Medicine Ltd}

Financial \& competing interests disclosure

DM Haas's work and time were supported by a grant from the Eunice Kennedy Shriver National Institute of Child Health and Human Development to the Obstetric-Fetal Pharmacology Research Units Network U10HD063094. The content is solely the responsibility of the author and does not necessarily represent the official views of the NIH. The author has no other relevant affiliations or financial involvement with any organization or entity with a financial interest in or financial conflict with the subject matter or materials discussed in the manuscript apart from those disclosed.

No writing assistance was utilized in the production of this manuscript. 
prescription drug other than prenatal vitamins and iron [1,2]. Not only do women with medical conditions become pregnant and require continued drug therapy, but pregnant women also develop conditions that require drug therapy. As pregnancy-specific dosing of drugs is almost universally lacking, providers are reliant upon dosing regimens in package inserts, usually derived from studies in healthy males [3]. In fact, the US National Research Act of 1974 codified the exclusion of reproductive-aged women from many trials to avoid accidental early fetal exposure to drugs. However, in 1993 the NIH in the US shifted the paradigm and required the inclusion of women in trials unless there was a reason not to. This included guidance on the inclusion of pregnant women.

Because pregnant women were excluded from clinical drug trials for so long there are only scant data regarding drug concentrations in pregnant women for many therapeutics. This trend does seem to be changing however. In the last 2 years, there were noted to be 264 registered clinical trials of drugs used in pregnancy [4]. Of these registered trials, 28 (10.6\%) specifically were noted to be reporting pharmacokinetic data in pregnant women [4]. This is important as reports recently have noted that drug concentrations in pregnant women are much lower than nonpregnant controls for many medications including antibiotic, antihypertensive and antiretroviral drugs to name a few [5-9]. Much of this change is due to the myriad physiological changes in pregnancy that are catalogued elsewhere [10]. The work of several international groups, including the US NIH-funded Obstetric-Fetal Pharmacology Research Units Network [101], is aimed at closing this gap in pharmacokinetic and pharmacodynamic data in pregnancy. The purpose of this review is to describe pharmacogenetics used in current therapeutics, to describe current obstetric pharmacogenetic findings and research, and to describe what is needed to ensure the future of pharmacogenetics and individualized pharmacotherapy in pregnancy.

\section{Pharmacogenetics currently utilized in therapeutics}

Pharmacogenetics refers to the study of individual candidate genes as a powerful tool to help explain interindividual variability in drug response [11]. This pertains to both therapeutic as well as adverse effects. It is well recognized that metabolized drugs exhibit the most pharmacokinetic variability. The majority of this variability is due to inconsistencies in the ability of enzymes in the liver and gastrointestinal tract to carry out drug metabolism. The key enzymes involved in metabolic variation include the CYP450 family of drugmetabolizing enzymes, which carry out phase 1 drug metabolism, but also the phase 2 enzymes, including the enzymes that carry out acetylation, glucuronidation, sulfation, methylation and the addition of glutathione. Many of these enzymes have SNPs that can lead to increased or decreased activity, accounting for some of the observed variation in drug concentrations and response. Additionally, there are SNPs responsible for receptor modifications that may impact the binding of a drug to its target. This could lead to no effect, decreased effect or too great of an effect. Pharmacogenetics studies seek to describe effect variation and relate it to genetic SNP differences in an effort to better predict response and minimize adverse effects.

Pharmacogenetics has had slow uptake into clinical practice however. Factors leading to this include: high cost of the tests, lack of knowledge about the tests and how to apply them by 
clinicians, the need for specialized laboratory equipment to perform the tests, difficulty with interpretation of tests, and the lack of proven utility of several of the pharmacogenetic tests [12].

Despite these limitations, there are several pharmacogenetic tests currently used in clinical practice. As of July 2011, there were 15 different drugs or drug classes with commercially available pharmacogenetic tests. Several of these tests are now standard of care in therapeutics. A mutation in the KRAS gene codon 12 or 13 leads to resistance to cetuximab therapy. Thus, the American Society of Clinical Oncology has recommended that all patients with metastatic colorectal carcinoma who are candidates for cetuximab therapy should have their tumor tested for KRAS mutations. If codon 12 or 13 mutations are detected, then the patients should not receive the expensive cetuximab therapy as part of their treatment [13]. The cutaneous adverse drug reaction Stevens-Johnson syndrome is a serious concern for people taking drugs such as abacavir and carbamazepine [14,15]. Pharmacogenetic screening for $H L A-B * 5701$ can help identify those taking abacavir most at risk for developing this severe adverse drug reaction. To avoid Stevens-Johnson syndrome, this test is now widely used for screening patients in need of abacavir in the developed world [16]. The BCR-ABL gene negates the benefits of imatinib therapy for those with chronic myelogenous leukemia and thus the therapy is not recommended for those carrying that gene. Other pharmacogenetic tests that similarly have data supporting their potential role for individualizing drug therapy are the CYP2D6 test for tamoxifen $[17,18]$ or venlafaxine [19], the CYP2C19 test for clopidogrel antiplatelet therapy [20], and the CYP2C9 and VKCOR test for those starting warfarin therapy [21-23].

These tests and pharmacogenetic findings are becoming much more common. In fact, one study revealed that nearly one-quarter of all outpatients received at least one drug with pharmacogenomic information in the label for that drug [24]. Table 1 displays a list of drugmetabolizing enzymes and receptors that have polymorphic expression and some of the drugs that are relevant to that drug. While pregnancy therapeutics is behind other therapeutic areas in researching pharmacogenetics, data are emerging in several areas that may pave the way toward a greater importance of pharmacogenetics in pregnancy.

\section{Codeine \& opioid pain}

Opioid analgesics frequently are used for peripartum pain relief. As codeine and other narcotic pain medications are prodrugs requiring conversion to morphine and other active metabolites for their action, metabolizing enzymes are important to consider. For instance codeine requires metabolism by CYP2D6 into the active metabolite morphine. CYP2D6 is an enzyme that is highly polymorphic and is actually induced through the course of pregnancy $[25,26]$. Women who possess certain SNPs in CYP2D6 are categorized as poor metabolizers (Table 1). These women do not receive adequate pain relief from codeine as it is not well transformed into active morphine. Conversely, some individuals possess many copies of the CYP2D6 gene and are either extensive metabolizers (EMs) or ultra-rapid metabolizers (UMs). These women would convert codeine to morphine in a normal way or in an excessive way, respectively. People who are UMs might get rapid pain relief but also be more prone to side effects [27-29]. The presence of these SNPs can be particularly 
relevant depending on the woman's SNPs in UGT. UGT facilitates the excretion of opioids from the body [27]. The combination of CYP2D6 UM status of the mother and infants with a $U G T B 7^{*} 2$ genotype, indicative of reduced activity, can lead to toxicity of morphine in breastfeeding infants [30]. Because these findings have explained infant deaths, the US FDA issued a Public Health Advisory for women who are breastfeeding and taking narcotics [102]. In addition, the EMA's Pharmacovigilance Risk Assessment Committee also discourages codeine use by breastfeeding women or for any patient who is known to be a CYP2D6 UM [103].

Thus, for women planning to breastfeed who will require narcotic pain medication in the postpartum period, codeine may not be the best choice for analgesia [31]. While other opioid pain medications also are metabolized by CYP2D6, many of them also are metabolized through other CYP450 pathways, thus potentially ameliorating some of the impact of CYP2D6 metabolism status on pain control and side effects. The importance of these SNPs with other opioids in the peripartum period is being investigated. However, it is being noted that pharmacogenetics is an important factor in life-threatening adverse events among opioid users [32]. This is an active area of research. While guidelines have not been issued as a result of this research yet, obstetric practitioners should be aware of developments in this area.

\section{Antihypertensive medications}

Hypertension complicates $12-22 \%$ of pregnancies [33]. Whether being treated for chronic hypertension or for acutely elevated blood pressures with preeclampsia, many pregnant women require antihypertensive drugs. $\beta$-blockers are commonly used antihypertensive drugs. Drugs in this category such as metoprolol and propranolol are metabolized by CYP2D6. As demonstrated already, CYP2D6 activity increases throughout pregnancy. Thus, later in pregnancy, someone who had previously been controlled on her medication may begin to show signs of worsening hypertension [34]. Up to 7\% of the US major ethnic populations are UMs, with gene duplication UMs as high as $45 \%$ in Asians [35,36]. As pregnancy progresses, EMs and UMs have more enzymatic activity, whereas poor metabolizers have suppressed activity [26,37]. Thus, practitioners who prescribe $\beta$-blockers must be cognizant that as pregnancy progresses, the needs for drug may change.

Atenolol is a $\beta$-blocker also used in obstetrics. Polymorphisms in the eNOS gene are associated with variations in the pharmacological response to atenolol. Patients with G498A polymorphism in the $e N O S$ gene have a better blood pressure response to atenolol. If confirmed in larger studies, it is possible that the presence of $e N O S$ polymorphisms could help inform atenolol antihypertensive therapy [38].

Hydralazine is commonly used for acute treatment of severe hypertension [39]. Hydralazine is metabolized by the enzyme NAT [40]. NAT has several polymorphisms that lead to reduced enzymatic activity. This would potentially lead to higher concentrations of hydralazine that might yield worsening side effects, such as hypotension. This has not been studied in pregnancy to date. If a pregnant woman was known to have one of these SNPs, it could lead to her not being administered hydralazine during a hypertensive emergency 
owing to the higher risk of hypotension and may lead to a different drug choice. This would be one way that pharmacogenetics might play a role in individualized antihypertensive therapy.

\section{Antidepressant drugs}

The mainstays of antidepressant therapy in pregnancy are SSRIs [41]. Several of the SSRI drugs are metabolized by CYP2D6 [104]. In addition, several of them, such as fluoxetine, also inhibit the enzyme. It is clear that even in women maintained on drug therapy, depression symptoms typically worsen as pregnancy progresses [42]. Drug concentrations of SSRIs also decrease in the third trimester. This is attributed to increased CYP2D6 activity $[43,44]$. One study using paroxetine found that CYP2D6 genotype accounted for differences in maternal plasma paroxetine concentrations during pregnancy [37]. In addition, as pregnancy progressed, depressive symptoms in women who were EMs and UMs increased significantly. The authors concluded that knowledge about a patient's CYP2D6 genotype is 'indispensable' when prescribing paroxetine [37].

There are concerns regarding SSRI use and neonatal irritability symptoms and potential small teratogenic risk increases [45]. It is possible that pharmacogenetic-informed prescribing could help tailor the dose to help minimize potential adverse effects. More research is needed on the pharmacogenetics of the adverse events associated with SSRI therapy. There are now investigators advocating for the use of pharmacogenetic models to inform therapeutic dosing decisions [46].

\section{Preterm labor therapy}

As the cause of the majority of neonatal morbidity and mortality, preterm labor is a major focus of obstetric practice. The use of tocolytic medications to stop preterm labor is commonplace but of varying success $[47,48]$. While many of the commonly used tocolytic medications are substrates of polymorphic enzymes or target polymorphic receptors, there is a paucity of data in this area. Whether the individual variation in success of tocolysis is due to a less-than-concrete definition of preterm labor, differing pathophysiology of preterm contractions or pharmacogenetic explanations, there remains work to be done in this area to better individualize therapy.

Nifedipine is a calcium channel blocker used in obstetrics to stop contractions and delay birth. It has been demonstrated that calcium channel blockers have a beneficial efficacy and safety profile over other tocolytic classes of medication [49-51]. Nifedipine is metabolized by the CYP3A family. Recent studies have demonstrated that polymorphisms in CYP3A5 and the use of CYP3A inhibitors can impact the concentration of nifedipine in maternal blood [52,53]. While this is preliminary work, efforts have been underway to predict drug concentrations in maternal blood based on CYP3A predicted activity [54]. As more data emerge regarding the impact of genotype on drug concentration and the correlation with pharmacodynamic changes of stopping contractions and preventing delivery, there may be clinical applications of pharmacogenetics to this therapy. As this is a developing field, however, more data are needed to populate and validate these models. 
The only FDA-approved drug for preterm labor is ritodrine. This $\beta$-adrenergic receptor $\left(\beta_{2} \mathrm{R}\right)$ agonist results in uterine smooth muscle relaxation. The side effects of ritodrine and other $\beta_{2} \mathrm{R}$ agonists such as terbutaline and hexoprenaline have lessened enthusiasm for these therapies. The EMA went so far as to restrict the use of these medicines to a maximum of 48 $\mathrm{h}$ and only in women between 22 and 37 weeks of gestation [105]. In addition, the FDA issued a black box warning against prolonged use of terbutaline for these reasons [106]. Even high drug concentrations of ritodrine have been noted not to inhibit labor [55]. Thus, it may be at the $\beta_{2} \mathrm{R}$ where differential response may be born. Some genotypes of the $\beta_{2} \mathrm{R}$ have been found to be protective against preterm delivery but the results did not show consistent genotype associations [56,57]. One study demonstrated that $\operatorname{Arg} 16$ homozygosity of the $\beta_{2} R$ improved the pregnancy outcome after hexoprenaline use [58]. We are unaware of any other pharmacogenetic study of $\beta_{2} \mathrm{R}$ agonists.

Prostaglandin inhibitors such as indomethacin have also been demonstrated to be effective in treatment of preterm labor [50,51]. Indomethacin is metabolized by the polymorphic CYP2C9 and CYP2C19 enzymes [59]. SNPs in these enzymes may affect the concentrations of indomethacin and its effectiveness in preterm labor therapy, but we are unaware of any studies in this area. As prostaglandin inhibitors also have fetal effects, they are typically limited to use earlier in the preterm period [60]. Magnesium sulfate is another commonly used tocolytic agent. We are also unaware of any pharmacogenetic studies on magnesium sulfate as a tocolytic.

Antenatal corticosteroid administration is the most important therapy that can be given to a woman in preterm labor [47]. Maternally administered to enhance the fetal lung maturation in anticipation of preterm birth, antenatal corticosteroids reduce both neonatal mortality and morbidity [61,62]. However, not all neonates receive the same benefit. Differences in neonatal respiratory outcomes are seen in different ethnic groups, independent of gestational age, weight and other sociodemographic factors [63-65]. In addition, respiratory distress syndrome (RDS)-related mortality has a racial disparity that cannot be explained by demographic factors [64]. Several studies are attempting to test for pharmacogenetic explanations for this response variability. Betamethasone and dexamethasone are the currently recommended options for antenatal corticosteroid therapy [47]. There are no currently published studies to our knowledge that describe genetic influences on corticosteroid drug concentrations in pregnancy. Much of the literature focuses on genotype associations with outcomes. For instance glucocorticoids act at the glucocorticoid receptor (GR). There are polymorphisms in the GR gene that can impact its response. Much of the work in the GR and glucocorticoid pathway genes has come from asthma research $[66,67]$. While some SNPs create less functional GR activity, many polymorphisms in the pathway genes lead to GR hypersensitivity [68]. Studies specifically of polymorphisms in GR have shown certain haplotypes that may help determine clinical response [69], where one specifically showed that a polymorphism in the GST-PI gene may have an effect on RDS [70]. In addition, a recent pharmacogenetic study looking at multiple $C Y P 3 A$ and other betamethasone metabolic pathway SNPs and glucocorticoid pathway genes found that both maternal and fetal genotypes were associated with RDS after betamethasone treatment when controlling for gestational age and a host of other sociodemographic factors [71]. These 
findings included a fetal $C Y P 3 A 7^{*} 1 E$ genotype with an odds ratio of 23.68 (95\% CI: $1.33-$ 420.6) for developing RDS. There were other SNPs significantly associated with long-term respiratory morbidity such as bronchopulmonary dysplasia from the same cohort [72]. While all of these studies are small and need to be confirmed in larger cohorts, there may be potential for pharmacogenetic variation to help explain some of the outcome differences from antenatal corticosteroids.

\section{Nausea \& vomiting of pregnancy}

Nausea and vomiting of pregnancy (NVP) is a very common disorder, affecting up to $80 \%$ of pregnant women [73]. Both mild and severe cases of NVP have a significant impact on the quality of a woman's life and can result in loss of time with family and time away from work $[74,75]$. Many drugs are used to counteract NVP. These include vitamin B6, doxylamine, promethazine, metoclopramide and ondansetron alone or in combination with each other to name a few. Response to these drugs varies. Anesthesia literature has documented that genotypes of drug-metabolizing enzymes and receptors may impact therapeutic effectiveness of several of these drugs. A CYP2D6 substrate, ondansetron is a drug whose failure has been linked to CYP2D6 EMs and UMs [76]. Many of the drugs commonly given for NVP are substrates for polymorphic CYP450 enzymes. In addition, many of the drugs act at the polymorphic serotonin receptor 5HT3. This receptor facilitates the role of serotonin as a mediator of nausea and vomiting [77]. Variants in the 5HT3B receptor are linked to increased nausea and vomiting due to increased response to serotonin binding [78]. For women with NVP, one study demonstrated that SNPs in 5HT3B leading to a high affinity receptor led to women needing more medication [79]. Other SNPs in the 5HT3A receptor were associated with more improvement in both NVP symptoms and quality of life [79]. This study may be an initial foray into pharmacogenetics of NVP and should be confirmed. However, it may lead to more individualized therapy for women with NVP who have genotypes that might make a certain therapeutic drug option less effective.

\section{Antiseizure drugs}

Seizure disorders affect up to $2 \%$ of the population. Many women thus become pregnant when taking drugs to prevent seizures. Many of these drugs are associated with teratogenic effects. Drug concentrations are often monitored in pregnancy as concentrations change. This often requires dose changes as the pregnancy progresses and in the postpartum period. Some of this can be explained by the metabolism of some of the drugs. For instance, phenytoin is metabolized by CYP2C 9 , a polymorphic enzyme that is induced in pregnancy [80]. Some of the newer seizure drugs have favorable teratogenic and therapeutic profiles [81]. One that is commonly used currently is lamotrigine. Lamotrigine clearance increases several-fold in pregnancy [82-84]. This can lead to the need for higher doses during pregnancy. Lamotrigine is metabolized through glucuronidation by enzymes that are both polymorphic and often induced in pregnancy [85].

\section{Obstetric anesthesia}

In addition to utilizing antihypertensive medications and oral opioids listed above, there are some potential areas where pharmacogenetics may influence obstetric anesthesia. 
Hypotension is a common side effect after spinal anesthesia. Response to stimulant therapy for this is affected by the $\beta_{2} \mathrm{R}$ genotype/haplotype [86]. In this study, less ephedrine was needed to treat the hypotension in women carrying one or two alleles of the variant. Landau points out that this may be one reason why numerous studies trying to prevent or treat hypotension during spinal anesthesia for cesarean have failed to define a single 'one size fits all' strategy [87]. Genetics may explain interindividual variation in this area. Additionally SNPs in the $\mu$-opioid receptor probably influence the pharmacodynamics of intrathecal fentanyl [88]. These are just a few of the several areas where obstetric anesthesia is embarking on pharmacogenetic research [87,89].

\section{Pharmacogenetic horizon areas in obstetrics}

There are a few other recent studies that highlight some areas where pharmacogenetics may be utilized in obstetric therapeutics and management. The genetics of preeclampsia have been analyzed multiple ways. The importance of both maternal and fetal genotype in this disorder is apparent [90]. The endothelial isoform of nitric oxide synthase may be important in the manifestations and the treatment of preeclampsia [38]. Smoking cessation is an important goal of prenatal care. Recent findings that fetal GSTT1 deletion significantly modifies the effect of smoking on birth weight may open windows into genotype and may impact therapy for growth restriction [91]. The treatment of gestational diabetes has undergone many changes in the last decade. The use of oral hypoglycemic agents has diminished the use of insulin for patients. However, with the recent finding that typical doses of glyburide for these women may lead to suboptimal drug concentrations [92], pharmacogenetic impact studies on drug concentration variability are underway.

\section{The patient's perspective}

The uptake of pharmacogenetics in clinical practice has been slow [12]. Much of this is due to the paucity of data and pharmacogenetic-driven therapeutic trials. However, there is also a lack of understanding on the part of clinicians. There is also a worry about how to best make patients understand the science and nuance of pharmacogenetics in relation to their medical therapy.

As researchers and practitioners postulate about future implementation, it is reassuring to know that in general, most surveyed populations support collecting biological specimens for research [93-95]. For pregnant women, the majority would give a specimen for DNA analysis by either blood (needlestick) or saliva [96]. Making the transition from research to clinical care, however, is less studied.

In an interesting follow-up study at Motherisk in Toronto, Madadi and colleagues asked participants in a pharmacogenetic study about the communication of their information back to them [97]. The diversity and complexity of questions that participants asked the investigators underscore the need for supportive communication of results in the context of personalized genetic information counseling. Some of the common suggestions by participants related to having a short amount of time between the test and the results [97]. This is particularly relevant to pregnancy where decision for therapy cannot wait for several years (the normal time cycle for research results). In addition, it was commonly brought up 
that genetic screening should be a routine part of prenatal screening or even to be carried out before pregnancy. The clear message was that patients want to know if their genetic information may impact their therapy or their babies. While this is only representative of a small pregnant population, it is an area that will need further work.

\section{Future perspective}

Achieving individualized therapy in pregnancy (and in all of medicine) is a reachable goal. Pharmacogenetics may be one tool to help achieve that goal. However, the current studies in these areas are underpowered and observational. More data that combine genotypes, pharmacokinetic information and pharmacodynamic outcomes are crucial to take steps forward. In particular, the outcomes that need to garner focus for obstetric therapeutics are the short- and long-term neonatal outcomes. These studies are expensive and difficult but truly needed to understand if pharmacogenetic-driven therapy is truly a step forward. Consideration of both maternal and fetal genotypes and building therapeutic models can help supply clinicians with strategies for treatment. However, they will rely on robust data to populate and validate the models. Only then will individualized pharmacotherapy in pregnancy utilizing pharmacogenetics be realized.

\section{References}

Papers of special note have been highlighted as:

- of interest

- of considerable interest

1. Andrade SE, Gurwitz JH, Davis RL, et al. Prescription drug use in pregnancy. Am J Obstet Gynecol. 2004; 191(2):398-407. [PubMed: 15343213]

2. Glover DD, Amonkar M, Rybeck BF, Tracy TS. Prescription, over-the-counter, and herbal medicine use in a rural, obstetric population. Am J Obstet Gynecol. 2003; 188(4):1039-1045. [PubMed: 12712107]

3. Haas DM. From no to yes: the history and ethics of including pregnant women in clinical trials. Clin Investig. 2011; 1(10):1349-1351.

4-. Endicott S, Haas DM. The current state of therapeutic drug trials in pregnancy. Clin Pharmacol Ther. 2012; 92(2):149-150. Review of currently registered drug trials in pregnancy. [PubMed: 22814658]

5. Andrew MA, Easterling TR, Carr DB, et al. Amoxicillin pharmacokinetics in pregnant women: modeling and simulations of dosage strategies. Clin Pharmacol Ther. 2007; 81(4):547-556. [PubMed: 17329990]

6. Buchanan ML, Easterling TR, Carr DB, et al. Clonidine pharmacokinetics in pregnancy. Drug Metab Dispos. 2009; 37(4):702-705. [PubMed: 19116263]

7. Unadkat JD, Wara DW, Hughes MD, et al. Pharmacokinetics and safety of indinavir in human immunodeficiency virus-infected pregnant women. Antimicrob Agents Chemother. 2007; 51(2): 783-786. Plasma indinavir concentrations are $68 \%$ lower in pregnancy than in nonpregnant women at the same dose. [PubMed: 17158945]

8. Beigi RH, Han K, Venkataramanan R, et al. Pharmacokinetics of oseltamivir among pregnant and nonpregnant women. Am J Obstet Gynecol. 2011; 204(6 Suppl 1):S84-S88. [PubMed: 21492826]

9. Hebert MF, Carr DB, Anderson GD, et al. Pharmacokinetics and pharmacodynamics of atenolol during pregnancy and postpartum. J Clin Pharmacol. 2005; 45(1):25-33. [PubMed: 15601802] 
10. Haas DM, Hebert MF, Soldin OP, et al. Pharmacotherapy and pregnancy: highlights from the Second International Conference for Individualized Pharmacotherapy in Pregnancy. Clin Transl Sci. 2009; 2(6):439-443. [PubMed: 20443937]

11. Haas, DM.; Flockhart, D. Pharmacogenomics in pregnancy. In: Mattison, D., editor. Clinical Pharmacology During Pregnancy. Elsevier; London, UK: 2012. p. 113-128.

12. Alfirevic A, Alfirevic Z, Pirmohamed M. Pharmacogenetics in reproductive and perinatal medicine. Pharmacogenomics. 2010; 11(1):65-79. [PubMed: 20017673]

13. Allegra CJ, Jessup JM, Somerfield MR, et al. American Society of Clinical Oncology provisional clinical opinion: testing for $K R A S$ gene mutations in patients with metastatic colorectal carcinoma to predict response to anti-epidermal growth factor receptor monoclonal antibody therapy. J Clin Oncol. 2009; 27(12):2091-2096. [PubMed: 19188670]

14. Aihara M. Pharmacogenetics of cutaneous adverse drug reactions. J Dermatol. 2011; 38(3):246254. [PubMed: 21342226]

15. Chung WH, Hung SI, Chen YT. Human leukocyte antigens and drug hypersensitivity. Curr Opin Allergy Clin Immunol. 2007; 7(4):317-323. [PubMed: 17620823]

16. Phillips EJ, Mallal SA. Pharmacogenetics of drug hypersensitivity. Pharmacogenomics. 2010; 11(7):973-987. [PubMed: 20602616]

17. Borges S, Desta Z, Jin Y, et al. Composite functional genetic and comedication CYP2D6 activity score in predicting tamoxifen drug exposure among breast cancer patients. J Clin Pharmacol. 2010; 50(4):450-458. [PubMed: 20081063]

18. Higgins MJ, Rae JM, Flockhart DA, Hayes DF, Stearns V. Pharmacogenetics of tamoxifen: who should undergo CYP2D6 genetic testing? J Natl Compr Canc Netw. 2009; 7(2):203-213. [PubMed: 19200418]

19. Lobello KW, Preskorn SH, Guico-Pabia CJ, et al. Cytochrome P450 2D6 phenotype predicts antidepressant efficacy of venlafaxine: a secondary analysis of 4 studies in major depressive disorder. J Clin Psychiatry. 2010; 71(11):1482-1487. Venlafaxine treatment in CYP2D6 extensive metabolizers demonstrates greater efficacy than treatment in poor metabolizers. [PubMed: 20441720]

20. Scott SA, Sangkuhl K, Gardner EE, et al. Clinical pharmacogenetics implementation consortium guidelines for cytochrome P450-2C19 (CYP2C19) genotype and clopidogrel therapy. Clin Pharmacol Ther. 2011; 90(2):328-332. [PubMed: 21716271]

21. Grossniklaus D. Testing of $V K O R C 1$ and $C Y P 2 C 9$ alleles to guide warfarin dosing. Test category: pharmacogenomic (treatment). PLoS Curr. 2010; 2 pii: RRN1155.

22-. Moreau C, Pautas E, Gouin-Thibault I, et al. Predicting the warfarin maintenance dose in elderly inpatients at treatment initiation: accuracy of dosing algorithms incorporating or not VKORC1/ CYP2C9 genotypes. J Thromb Haemost. 2011; 9(4):711-718. VKORC1 is the best predictor of warfarin maintenance dose. [PubMed: 21255252]

23. Zambon CF, Pengo V, Padrini R, et al. VKORC1, CYP2C9 and CYP4F2 genetic-based algorithm for warfarin dosing: an Italian retrospective study. Pharmacogenomics. 2011; 12(1):15-25. [PubMed: 21174619]

24-. Frueh FW, Amur S, Mummaneni P, et al. Pharmacogenomic biomarker information in drug labels approved by the United States Food and Drug Administration: prevalence of related drug use. Pharmacotherapy. 2008; 28(8):992-998. Nearly a quarter of all outpatients receive one or more drugs that have pharmacogenetic information on the label. [PubMed: 18657016]

25. Bernard S, Neville KA, Nguyen AT, Flockhart DA. Interethnic differences in genetic polymorphisms of CYP2D6 in the U.S. population: clinical implications. Oncologist. 2006; 11(2): 126-135. [PubMed: 16476833]

26-. Wadelius M, Darj E, Frenne G, Rane A. Induction of CYP2D6 in pregnancy. Clin Pharmacol Ther. 1997; 62(4):400-407. Pregnancy is the only known inducer of CYP2D6. [PubMed: 9357391]

27. Madadi P, Avard D, Koren G. Pharmacogenetics of opioids for the treatment of acute maternal pain during pregnancy and lactation. Curr Drug Metab. 2012; 13(6):721-727. [PubMed: 22452458] 
28. Vandervaart S, Berger H, Sistonen J, et al. CYP2D6 polymorphisms and codeine analgesia in postpartum pain management: a pilot study. Ther Drug Monit. 2011; 33(4):425-432. [PubMed: 21743374]

29. Kirchheiner J, Schmidt H, Tzvetkov M, et al. Pharmacokinetics of codeine and its metabolite morphine in ultra-rapid metabolizers due to CYP2D6 duplication. Pharmacogenomics J. 2007; 7(4):257-265. [PubMed: 16819548]

30. Madadi P, Ross CJ, Hayden MR, et al. Pharmacogenetics of neonatal opioid toxicity following maternal use of codeine during breastfeeding: a case-control study. Clin Pharmacol Ther. 2009; 85(1):31-35. [PubMed: 18719619]

31. Caraco Y, Sheller J, Wood AJ. Pharmacogenetic determination of the effects of codeine and prediction of drug interactions. J Pharmacol Exp Ther. 1996; 278(3):1165-1174. [PubMed: 8819499]

32. Madadi P, Sistonen J, Silverman G, et al. Life-threatening adverse events following therapeutic opioid administration in adults: is pharmacogenetic analysis useful? Pain Res Manag. 2013; 18(3): 133-136. [PubMed: 23748253]

33. ACOG Committee on Practice Bulletins - Obstetrics. ACOG practice bulletin Diagnosis and management of preeclampsia and eclampsia Number 33, January 2002. Obstet Gynecol. 2002; 99(1):159-167. [PubMed: 16175681]

34. Haas DM, D'Alton M. Pharmacogenetics and other reasons why drugs can fail in pregnancy: higher dose or different drug? Obstet Gynecol. 2012; 120(5):1176-1179. [PubMed: 23090536]

35. Bradford LD. CYP2D6 allele frequency in European Caucasians, Asians, Africans and their descendants. Pharmacogenomics. 2002; 3(2):229-243. [PubMed: 11972444]

36. Hosono N, Kato M, Kiyotani K, et al. CYP2D6 genotyping for functional-gene dosage analysis by allele copy number detection. Clin Chem. 2009; 55(8):1546-1554. [PubMed: 19541866]

37. Ververs FF, Voorbij HA, Zwarts P, et al. Effect of cytochrome P450 2D6 genotype on maternal paroxetine plasma concentrations during pregnancy. Clin Pharmacokinet. 2009; 48(10):677-683. [PubMed: 19743889]

38. Williams PJ, Morgan L. The role of genetics in pre-eclampsia and potential pharmacogenomic interventions. Pharmgenomics Pers Med. 2012; 5:37-51. [PubMed: 23226061]

39. Duley L, Henderson-Smart DJ, Meher S. Drugs for treatment of very high blood pressure during pregnancy. Cochrane Database Syst Rev. 2006; 3:CD001449. [PubMed: 16855969]

40. Lemke LE, McQueen CA. Acetylation and its role in the mutagenicity of the antihypertensive agent hydralazine. Drug Metab Dispos. 1995; 23(5):559-565. [PubMed: 7587931]

41. O’Keane V, Marsh MS. Depression during pregnancy. BMJ. 2007; 334(7601):1003-1005. [PubMed: 17494021]

42. Cohen LS, Altshuler LL, Harlow BL, et al. Relapse of major depression during pregnancy in women who maintain or discontinue antidepressant treatment. JAMA. 2006; 295(5):499-507. [PubMed: 16449615]

43. Sit DK, Perel JM, Helsel JC, Wisner KL. Changes in antidepressant metabolism and dosing across pregnancy and early postpartum. J Clin Psychiatry. 2008; 69(4):652-658. [PubMed: 18426260]

44. Heikkinen T, Ekblad U, Palo P, Laine K. Pharmacokinetics of fluoxetine and norfluoxetine in pregnancy and lactation. Clin Pharmacol Ther. 2003; 73(4):330-337. [PubMed: 12709723]

45. Wisner KL, Sit DK, Hanusa BH, et al. Major depression and antidepressant treatment: impact on pregnancy and neonatal outcomes. Am J Psychiatry. 2009; 166(5):557-566. [PubMed: 19289451]

46. Kirchheiner J, Brosen K, Dahl ML, et al. CYP2D6 and CYP2C19 genotype-based dose recommendations for antidepressants: a first step towards subpopulation-specific dosages. Acta Psychiatr Scand. 2001; 104(3):173-192. [PubMed: 11531654]

47. American College of Obstetricians and Gynecologists, Committee on Practice Bulletins Obstetrics. ACOG practice bulletin no 127: management of preterm labor. Obstet Gynecol. 2012; 119(6):1308-1317. [PubMed: 22617615]

48. Caritis S. Adverse effects of tocolytic therapy. BJOG. 2005; 112(Suppl 1):S74-S78.

49. Cararach V, Palacio M, Martinez S, et al. Nifedipine versus ritodrine for suppression of preterm labor. Comparison of their efficacy and secondary effects. Eur J Obstet Gynecol Reprod Biol. 2006; 127(2):204-208. [PubMed: 16310305] 
50-. Haas DM, Imperiale TF, Kirkpatrick PR, Klein RW, Zollinger TW, Golichowski AM. Tocolytic therapy: a meta-analysis and decision analysis. Obstet Gynecol. 2009; 113(3):585-594. Tocolytic systematic review and the first formal network meta-analysis in obstetric therapeutics demonstrating that prostaglandin inhibitors and calcium channel blockers tend to have the best efficacy-safety profile compared with placebo. [PubMed: 19300321]

51. Haas DM, Caldwell DM, Kirkpatrick P, McIntosh JJ, Welton NJ. Tocolytic therapy for preterm delivery: systematic review and network meta-analysis. BMJ. 2012; 345:e6226. [PubMed: 23048010]

52. Haas DM, Quinney SK, Clay JM, et al. Nifedipine pharmacokinetics are influenced by CYP3A5 genotype when used as a preterm labor tocolytic. Am J Perinatol. 2013; 30(4):275-281. [PubMed: 22875663]

53. Haas DM, Quinney SK, McCormick CL, Jones DR, Renbarger JL. A pilot study of the impact of genotype on nifedipine pharmacokinetics when used as a tocolytic. J Matern Fetal Neonatal Med. 2012; 25(4):419-423. [PubMed: 21644845]

54. Quinney SK, Mohamed AN, Hebert MF, et al. A semi-mechanistic metabolism model of CYP3A substrates in pregnancy: predicting changes in midazolam and nifedipine pharmacokinetics. CPT Pharmacomet Syst Pharmacol. 2012; 1:e2.

55. Caritis SN, Lin LS, Toig G, Wong LK. Pharmacodynamics of ritodrine in pregnant women during preterm labor. Am J Obstet Gynecol. 1983; 147(7):752-759. [PubMed: 6650595]

56. Landau R, Xie HG, Dishy V, et al. Beta2-adrenergic receptor genotype and preterm delivery. Am J Obstet Gynecol. 2002; 187(5):1294-1298. [PubMed: 12439523]

57. Ozkur M, Dogulu F, Ozkur A, Gokmen B, Inaloz SS, Aynacioglu AS. Association of the Gln27Glu polymorphism of the beta-2-adrenergic receptor with preterm labor. Int J Gynaecol Obstet. 2002; 77(3):209-215. [PubMed: 12065131]

58. Landau R, Morales MA, Antonarakis SE, Blouin JL, Smiley RM. Arg16 homozygosity of the beta2-adrenergic receptor improves the outcome after beta2-agonist tocolysis for preterm labor. Clin Pharmacol Ther. 2005; 78(6):656-663. [PubMed: 16338281]

59. Nakajima M, Inoue T, Shimada N, Tokudome S, Yamamoto T, Kuroiwa Y. Cytochrome P450 2C9 catalyzes indomethacin $O$-demethylation in human liver microsomes. Drug Metab Dispos. 1998; 26(3):261-266. [PubMed: 9492390]

60m. Norton ME, Merrill J, Cooper BA, Kuller JA, Clyman RI. Neonatal complications after the administration of indomethacin for preterm labor. N Engl J Med. 1993; 329(22):1602-1607. Giving antenatal corticosteroids prior to preterm birth effectively reduces neonatal respiratory distress syndrome, intraventricular hemorrhage, necrotizing enterocolitis and death. [PubMed: 8232428]

61. Crowley P. Prophylactic corticosteroids for preterm birth. Cochrane Database Syst Rev. 2000; 2:CD000065. [PubMed: 10796110]

62. Roberts D, Dalziel SR. Antenatal corticosteroids for accelerating fetal lung maturation for women at risk of preterm birth. Cochrane Database Syst Rev. 2009; 3:CD004454. [PubMed: 16856047]

63. Frisbie WP, Forbes D, Pullum SG. Compromised birth outcomes and infant mortality among racial and ethnic groups. Demography. 1996; 33(4):469-481. [PubMed: 8939419]

64. Frisbie WP, Song SE, Powers DA, Street JA. The increasing racial disparity in infant mortality: respiratory distress syndrome and other causes. Demography. 2004; 41(4):773-800. [PubMed: 15622954]

65. Kavvadia V, Greenough A, Dimitriou G, Hooper R. Influence of ethnic origin on respiratory distress syndrome in very premature infants. Arch Dis Child Fetal Neonatal Ed. 1998; 78(1):F25F28. [PubMed: 9536836]

66. Tantisira K, Weiss S, Tantisira K, Weiss S. The pharmacogenetics of asthma treatment. Curr Allergy Asthma Rep. 2009; 9(1):10-17. [PubMed: 19063819]

67. Tantisira KG, Lake S, Silverman ES, et al. Corticosteroid pharmacogenetics: association of sequence variants in CRHR1 with improved lung function in asthmatics treated with inhaled corticosteroids. Hum Mol Genet. 2004; 13(13):1353-1359. [PubMed: 15128701]

68. van Rossum EF, van den Akker EL. Glucocorticoid resistance. Endocr Dev. 2011; 20:127-136. [PubMed: 21164266] 
69. Stevens A, Ray DW, Zeggini E, et al. Glucocorticoid sensitivity is determined by a specific glucocorticoid receptor haplotype. J Clin Endocrinol Metab. 2004; 89(2):892-897. [PubMed: 14764810]

70. Oretti C, Marino S, Mosca F, et al. Glutathione-S-transferase-P1 I105V polymorphism and response to antenatal betamethasone in the prevention of respiratory distress syndrome. Eur J Clin Pharmacol. 2009; 65(5):483-491. [PubMed: 19183974]

71. Haas DM, Lehmann AS, Skaar T, et al. The impact of drug metabolizing enzyme polymorphisms on outcomes after antenatal corticosteroid use. Am J Obstet Gynecol. 2012; 206(5):447.e417447.e424. [PubMed: 22445700]

72. Haas DM, Dantzer J, Lehmann AS, et al. The impact of glucocorticoid polymorphisms on markers of neonatal respiratory disease after antenatal betamethasone administration. Am J Obstet Gynecol. 2013; 208(3):215.e211-215.e216. [PubMed: 23295978]

73. Emelianova S, Mazzotta P, Einarson A, Koren G. Prevalence and severity of nausea and vomiting of pregnancy and effect of vitamin supplementation. Clin Invest Med. 1999; 22(3):106-110. [PubMed: 10410832]

74. Mazzotta P, Maltepe C, Navioz Y, Magee LA, Koren G. Attitudes, management and consequences of nausea and vomiting of pregnancy in the United States and Canada. Int J Gynaecol Obstet. 2000; 70(3):359-365. [PubMed: 10967171]

75. Mazzotta P, Stewart D, Atanackovic G, Koren G, Magee LA. Psychosocial morbidity among women with nausea and vomiting of pregnancy: prevalence and association with anti-emetic therapy. J Psychosom Obstet Gynaecol. 2000; 21(3):129-136. [PubMed: 11076334]

76. Candiotti KA, Birnbach DJ, Lubarsky DA, et al. The impact of pharmacogenomics on postoperative nausea and vomiting: do $C Y P 2 D 6$ allele copy number and polymorphisms affect the success or failure of ondansetron prophylaxis? Anesthesiology. 2005; 102(3):543-549. [PubMed: 15731591]

77. Andrews PL, Bhandari P. The 5-hydroxytryptamine receptor antagonists as antiemetics: preclinical evaluation and mechanism of action. Eur J Cancer. 1993; 29A(Suppl 1):S11-S16. [PubMed: 8427719]

78. Krzywkowski K, Davies PA, Feinberg-Zadek PL, Brauner-Osborne H, Jensen AA. High-frequency $H T R 3 B$ variant associated with major depression dramatically augments the signaling of the human 5-HT3AB receptor. Proc Natl Acad Sci USA. 2008; 105(2):722-727. [PubMed: 18184810]

79-. Lehmann A, Renbarger J, McCormick C, Topletz A, Rouse C, Haas D. Pharmacogenetic predictors of nausea and vomiting of pregnancy severity and response to antiemetic therapy: a pilot study. BMC Pregnancy Childbirth. 2013; 13(1):132. Review of therapeutic areas anesthesia providers must be concerned with and their pharmacogenetic implications. [PubMed: 23786674]

80. Swen JJ, Nijenhuis M, De Boer A, et al. Pharmacogenetics: from bench to byte - an update of guidelines. Clin Pharmacol Ther. 2011; 89(5):662-673. [PubMed: 21412232]

81. Laroche SM, Helmers SL. The new antiepileptic drugs: clinical applications. JAMA. 2004; 291(5): 615-620. [PubMed: 14762041]

82. Sabers A. Algorithm for lamotrigine dose adjustment before, during, and after pregnancy. Acta Neurol Scand. 2012; 126(1):e1-e4. [PubMed: 22150770]

83. Pennell PB, Peng L, Newport DJ, et al. Lamotrigine in pregnancy: clearance, therapeutic drug monitoring, and seizure frequency. Neurology. 2008; 70(22 Pt 2):2130-2136. [PubMed: 18046009]

84. Tran TA, Leppik IE, Blesi K, Sathanandan ST, Remmel R. Lamotrigine clearance during pregnancy. Neurology. 2002; 59(2):251-255. [PubMed: 12136066]

85. Chen H, Yang K, Choi S, Fischer JH, Jeong H. Up-regulation of UDP-glucuronosyltransferase (UGT) 1A4 by 17beta-estradiol: a potential mechanism of increased lamotrigine elimination in pregnancy. Drug Metab Dispos. 2009; 37(9):1841-1847. [PubMed: 19546240]

86. Smiley RM, Blouin JL, Negron M, Landau R. Beta2-adrenoceptor genotype affects vasopressor requirements during spinal anesthesia for cesarean delivery. Anesthesiology. 2006; 104(4):644650. [PubMed: 16571957]

87. Landau R. Pharmacogenetic influences in obstetric anaesthesia. Best Pract Res Clin Obstet Gynaecol. 2010; 24(3):277-287. [PubMed: 20064747] 
88. Loubert C, Hinova A, Fernando R. Update on modern neuraxial analgesia in labour: a review of the literature of the last 5 years. Anaesthesia. 2011; 66(3):191-212. [PubMed: 21320088]

89. Landau R. Pharmacogenetics and obstetric anesthesia. Int Anesthesiol Clin. 2007; 45(1):1-15. [PubMed: 17215696]

90. Disentangling fetal and maternal susceptibility for pre-eclampsia: a British multicenter candidategene study. Am J Hum Genet. 2005; 77(1):127-131. [PubMed: 15889386]

91. Aagaard-Tillery K, Spong CY, Thom E, et al. Pharmacogenomics of maternal tobacco use: metabolic gene polymorphisms and risk of adverse pregnancy outcomes. Obstet Gynecol. 2010; 115(3):568-577. [PubMed: 20177288]

92. Hebert MF, Ma X, Naraharisetti SB, et al. Are we optimizing gestational diabetes treatment with glyburide? The pharmacologic basis for better clinical practice. Clin Pharmacol Ther. 2009; 85(6): 607-614. [PubMed: 19295505]

93. Stolt UG, Helgesson G, Liss PE, Svensson T, Ludvigsson J. Information and informed consent in a longitudinal screening involving children: a questionnaire survey. Eur J Hum Genet. 2005; 13(3): 376-383. [PubMed: 15657607]

94. Stolt UG, Liss PE, Svensson T, Ludvigsson J. Attitudes to bioethical issues: a case study of a screening project. Soc Sci Med. 2002; 54(9):1333-1344. [PubMed: 12058850]

95. Wendler D. One-time general consent for research on biological samples. BMJ. 2006; 332(7540): 544-547. [PubMed: 16513715]

96. Haas DM, Renbarger JL, Meslin EM, Drabiak K, Flockhart D. Patient attitudes toward genotyping in an Urban Women's Health Clinic. Obstet Gynecol. 2008; 112(5):1023-1028. [PubMed: 18978101]

97. Madadi P, Joly Y, Avard D, et al. The communication of pharmacogenetic research results: participants weigh in on their informational needs in a pilot study. J Popul Ther Clin Pharmacol. 2011; 18:e152-e155. [PubMed: 21467605]

\section{Websites}

101. Obstetric-Fetal Pharmacology Research Units Network. http://opru.rti.org

102. US FDA Public Health Advisory. Use of Codeine By Some Breastfeeding Mothers May Lead To Life-Threatening Side Effects In Nursing Babies. 2007. www.fda.gov/Drugs/DrugSafety/ PostmarketDrugSafetyInformationforPatientsandProviders/ DrugSafetyInformationforHeathcareProfessionals/PublicHealthAdvisories/ucm054717.htm

103. European Medicines Agency. Restrictions on use of codeine for pain relief in children. 2013. www.ema.europa.eu/docs/en_GB/document_library/Press_release/2013/06/WC500144851.pdf

104. CYP450 Drug Interaction Table. http://medicine.iupui.edu/clinpharm/ddis/table.aspx

105. European Medicines Agency. Restrictions on use of short-acting beta-agonists in obstetric indications. 2013. www.ema.europa.eu/docs/en_GB/document_library/Referrals_document/ Short-acting_beta-agonists/Position_provided_by_CMDh/WC500153129.pdf

106. US FDA Drug Safety Communication. New warnings against use of terbutaline to treat preterm labor. www.fda.gov/Drugs/DrugSafety/ucm243539.htm 


\section{Executive summary}

- 'The right drug at the right dose at the right time for the right patient' is the ideal for individualized therapeutics.

- Most pregnant women take therapeutic drugs during their pregnancy.

- There is a paucity of pharmacokinetic and pharmacogenetic studies particularly relating to pregnant women. This has delayed development in the field.

- Pharmacogenetic tests are used in other areas of medicine to help guide therapy. These include tests for the drugs cetuximab, abacavir, carbamazepine and imatinib. Other drugs with information supporting pharmacogenetic testing but not yet commonly used are tamoxifen, venlafaxine, clopidogrel and warfarin.

- Breastfeeding women who have genotypes expressing CYP2D6 (extensive or ultrarapid metabolizers) who also have a $U G T B 7 * 2$ genotype may be at higher risk for morphine toxicity in their infants. Thus a public health advisory warns about this potential problem. SNPs in CYP2D6 can also play a role in maternal pain control from other opioid drugs.

- Antihypertensive drugs such as $\beta$-blockers are metabolized through CYP2D6, which may explain some of the variability in response. Other antihypertensive drugs are also metabolized through polymorphic enzyme pathways.

- Some studies on SSRIs have found that polymorphisms in CYP450 enzymes may play a role in their effectiveness. More studies are needed, particularly in pregnancy relating to neonatal irritability syndrome.

- Preterm labor tocolytics are metabolized by polymorphic pathways or act at polymorphic receptors. There are limited data regarding the impact of SNPs on drug concentrations or effect.

- Some polymorphisms in glucocorticoid receptor pathways and CYP450s may be associated with neonatal respiratory outcomes after antenatal corticosteroid therapy.

- Drugs used for nausea and vomiting of pregnancy may demonstrate different responses based on serotonin receptor SNPs.

- Patients have noted that they would like genetic information returned, particularly if it would impact their future care or their baby's health.

- There is a continuing imperative for more data combining pharmacokinetics, pharmacodynamics and pharmacogenetics in order to build optimal therapeutic models. The focus of these models needs to be on short- and long-term newborn outcome optimization. 


\section{Table 1}

Drug-metabolizing enzymes and selected receptors with known polymorphisms affecting drug concentrations and/or response and some commonly used drugs in pregnancy that are substrates of that enzyme.

\begin{tabular}{|c|c|}
\hline Enzyme/receptor and specific SNP and functional significance & Drugs metabolized \\
\hline $\begin{array}{l}\text { CYP2D6 } \\
* 1 / * 1 \text { with multiple copies }=\text { ultrarapid metabolizer } \\
* 4 / * 4, * 4 / * 5, * 5 / * 5=\text { poor metabolizer } \\
* 1 / * 1, * 1 / * 2, * 2 / * 2=\text { extensive metabolizer }\end{array}$ & $\begin{array}{l}\text { Codeine, clonidine, fluoxetine, paroxetine, venlafaxine, } \\
\text { metoprolol, metoclopramide, ondansetron and } \\
\text { promethazine }\end{array}$ \\
\hline $\begin{array}{l}\text { CYP2C9 } \\
* 1=\text { normal enzymatic activity } \\
* 3 / * 3=\text { decreased enzymatic activity (warfarin dose adjustment needed) }\end{array}$ & Fluoxetine, glyburide, ibuprofen and warfarin \\
\hline $\begin{array}{l}\text { CYP2C19 } \\
* 1 / * 1=\text { normal enzymatic activity } \\
* 17 / 17=\text { ultrarapid metabolizer } \\
* 2 / * 2, * 3 / * 3, * 2 / * 3=\text { poor metabolizer }\end{array}$ & $\begin{array}{l}\text { Omeprazole and other proton pump inhibitors, phenytoin } \\
\text { and propranolol }\end{array}$ \\
\hline $\begin{array}{l}\text { CYP3A } \\
C Y P 3 A 4^{*} 1 B=\text { decreased activity } \\
\text { CYP } 3 A 5^{*} 3=\text { decreased activity } \\
\text { CYP } 3 A 7=\text { some polymorphisms allow this fetal enzyme to persist into } \\
\text { adulthood }\end{array}$ & $\begin{array}{l}\text { Chlorpheniramine, dexamethasone, indinavir and other } \\
\text { HIV antivirals, methadone, midazolam, nifedipine and } \\
\text { other calcium channel blockers, and propranolol }\end{array}$ \\
\hline $\begin{array}{l}\text { CYP2B6 } \\
* 6=\text { decreased enzymatic activity }\end{array}$ & Bupropion and methadone \\
\hline $\begin{array}{l}5 \mathrm{HT}_{3 \mathrm{~B}} \text { receptor variant }=\text { high affinity receptor } \\
5 \mathrm{HT}_{3 \mathrm{~A}} \text { receptor variant }=\text { increased expression of subunit }\end{array}$ & Ondansetron and SSRI drugs \\
\hline $\begin{array}{l}\beta_{2} \text { adrenergic receptor } \\
\text { Arg16Gly }=\text { enhanced agonist-induced desensitization } \\
\text { Gln27Glu = resistance to desensitization }\end{array}$ & Ritodrine, terbutaline and hexoprenaline \\
\hline $\begin{array}{l}\text { Glucocorticoid receptor NR3C1 } \\
\mathrm{N} 363 \mathrm{~S}=\text { hypersensitivity } \\
\text { BclI = hypersensitivity }\end{array}$ & Betamethasone and dexamethasone \\
\hline GST-P1 Ile105Val = reduced enzyme activity & Betamethasone and dexamethasone \\
\hline
\end{tabular}

List not comprehensive. 